\title{
Sub-100 nm Lithography with Using Pulsed Plasma Graft- polymerized Styrene and E-Beam Excited Plasma
}

\author{
Shinzo Morita, Shinji Ogawa, Tomoya Yamada and Ryoichi Inanami \\ Department of Electrical and Electronic Engineering and Information Engineering, \\ Nagoya University, Nagoya 464-01
}

Keywords: graft-polymerized styrene, e-beam excited plasma, sub-100nm lithography

\section{Introduction}

There are great interests in a sub- $100 \mathrm{~nm}$ lithography and more fine pattern fabrication for a future integrated circuit and quantum electronic devices like as a single electron transistor(SET) working at a room temperature. To realize such a quantum device fabrication, there are several approaches with and without a conventional lithography[1-4].

The lithographical technologies for such a fine pattern fabrication, namely the resist processes and etching processes must be improved significantly. For the resist, the thickness of resist film must be decreased from 100 to a few $10 \mathrm{~nm}$. Therefore a spin coated resist system have several problems that an uniform coating becomes very difficult for such a thin layer and the thickness is too thin to sustain the film during the plasma etching. To solve the problems, a new resist system and a new etching method must be developed. We proposed a pulsed plasma polymerized resist and en electronbeam excited plasma(EBEP) etching.

The pulsed plasma polymerization is a dry resist coating method proposed by us and the resist coating was performed uniformly to a thickness of nanometer level[5]. For the process, we previously developed several reactors and improved the resist characteristics. 0.5 micron lines and spaces pattern fabrication at $2 \mathrm{mC}$ was attained for the plasma polymerized styrene resist by a gas flow type reactor[6]. The pulsed plasma graft-polymerization is an advanced technology for the resist formation[7]. Practically the resist sensitivity was improved to $60 \mu \mathrm{C}$ for the film thickness of $2 \mu$ $\mathrm{m}[5]$. However the developed pattem size was limited to a few $\mu \mathrm{m}$ because of the electron-beam patterning system. In this paper, we evaluated the resist by a new electron beam patterning system with decreasing the resist thickness.
For the etching, we adopted a new concept plasma excitation method. Usually the plasma must have a moderate condition for the fine structure etching, namely low pressure plasma and low ion energy. There are several plasma sources, for example ECR, ICP, Helicon Wave Plasma, and so on, however they must keep a high power level to sustain the plasma at the low pressure like as 1 mTorr level. or more lower pressure. Therefore we proposed a new concept plasma generation, namely an electron beam excited plasma(EBEP)[8-10]. It was proved that the EBEP has a profitable characteristic for the plasma etching.

\section{Experimental}

Plasma polymerization was carried out by a capacitively coupled pulsed RF plasma[7]. As a monomer, styrene vapor was used for the film formation, where the film is expected to work as a -negative resist. The patterning on the resist was performed by an electron-beam patterning system, JBX-6000SG(JEOL).

The EBEP reactor was composed with an electron-beam source and a reaction chamber. Thermally emitted electrons from a tungsten filament were used as an E-Beam source. The EBeam was transferred into the reaction camber through an interface film. For the transfer, the electron-beam was accelerated to a few thousand $\mathrm{eV}$ for the interface film of 1 micron, where a polyimide thin film was newly developed as a thermally stable film. To evaluate the EBEP etching reactor, a conventional resist system was used. Whereas a chemically amplification negative resist, SAL610(Shipley) was used and sub-100 nm pattern was fabricated by the electron-beam patterning system. $\mathrm{CF}_{4}$ was used as an etching gas because the gas is widely used for the etching of $\mathrm{Si}$ wafer. Si wafer was a phosphate-doped n-type 
$<100>$ with a thickness of $400 \mu \mathrm{m}$.

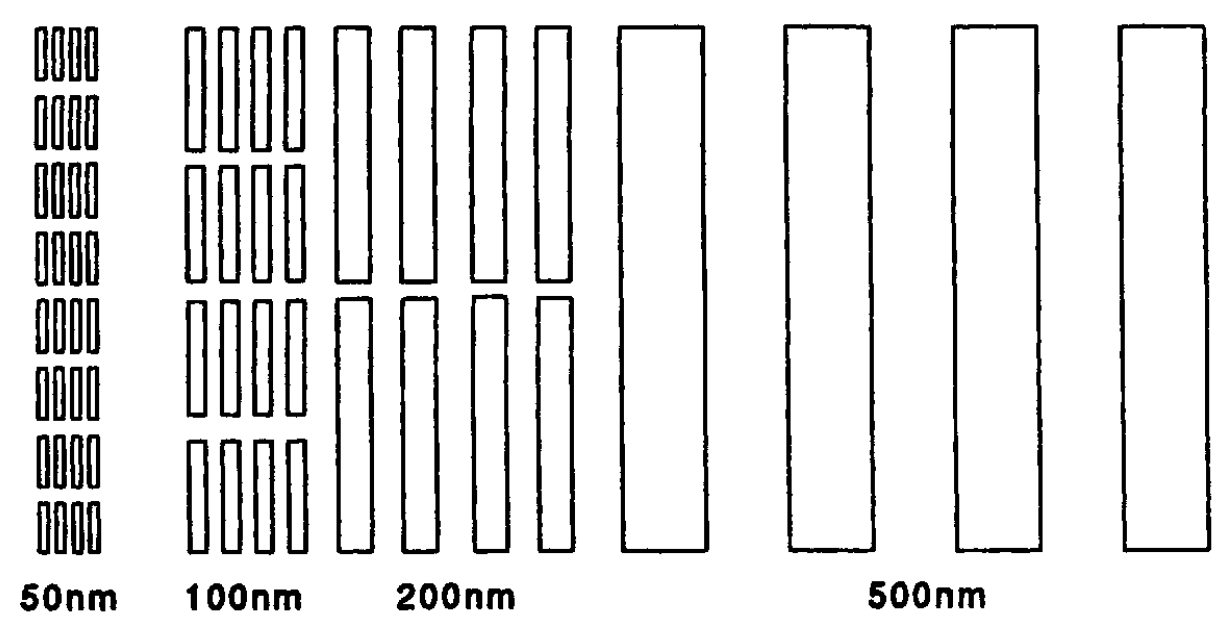

(a) Electron-beam delineated patterns

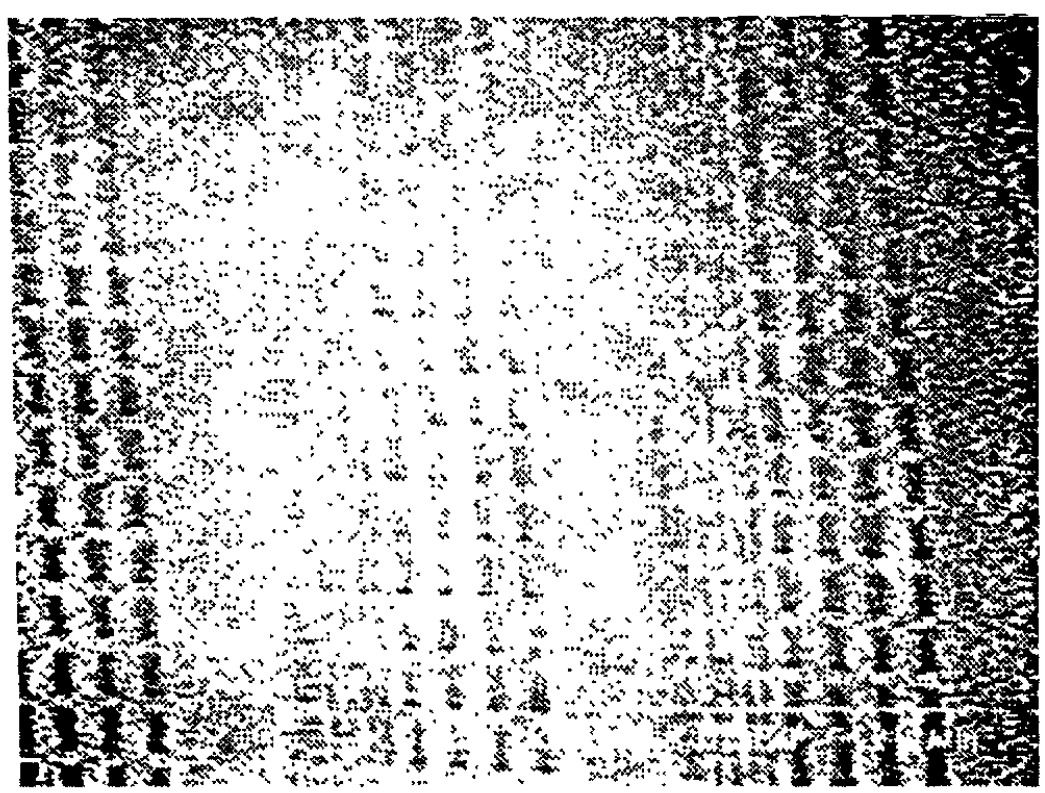

(b) Developed resist patterns taken by a SEM

Fig. 1. Electron-beam delineated patterns

\section{Results and Discussions}

\subsection{Pulsed Plasma Polymerized Styrene Resist}

The pulsed plasma graft-polymerized styrene film was formed as followings, initially a pulsed plasma polymerized styrene film is coated on the substrate and then the film is exposed to a styrene vapor after turning off the discharge. The initial pulsed plasma polymerized styrene was formed at a discharge frequency of $13.56 \mathrm{MHz}$, a pressure of 0.5 Torr, an on/off ration of $1: 9$ at a pulse period of $1 \mathrm{sec}$ in a styrene vapor. After that, graftpolymerization was carried out for $\mathbf{0 - 2 0 0 ~} \mathrm{min}$ in styrene vapor. The obtained film thickness was 200 $\mathrm{nm}$. The resist was patterned by an electron-beam patterning system at the doses from 50-500 $\mu \mathrm{C}$. The patterned resist was developed by the hexane and acetone mixture(the ratio was 10:1) for $30 \mathrm{sec}$. The patterned structure formed at $500 \mu \mathrm{C}$ is shown in Fig. 1 taken by SEM, where delineated and developed pattern are indicated in the same figure. The $200 \mathrm{~nm}$ pattern structure was recongnized in the photograph, and $100 \mathrm{~nm}$ patterns was not be resolved in the figure. The 50 nm pattern was disappeared form the substrate during the processes.

In the previous experiment, we developed 500 
nm pattern clearly in the film formed by an gas flow type reactor. From the experience, the improved pattern resolution for the finer pattern structure will be realized if the polymerization condition will be optimized.

\subsection{EBEP Etching}

In the previous experiment, the transmitted EBeam current through the interface was not exceeded $1 \mathrm{~mA}$, so the plasma could not be excited only by the E-Beam. For the experiments, polyester film of $1 \mu \mathrm{m}$ was used as an interface. The film melts at around $100 \mathrm{C}$. In order to increase the transmitted E-Beam current, the interface material was replaced by polyimide and a new ultra thin interface film with $1 \mu \mathrm{m}$ thick was fabricated by a spin coating method with using polyimide solution, SP-811, Toray Co. Inc.. The transmitted E-Beam current was recorded to be $3 \mathrm{~mA}$. However the E-Beam could not excited the plasma in the reaction chamber. Therefore, the curing temperature of polyimide thin film was changed from $350 \mathrm{C}$ to a lower temperature. For the interface treated at $300 \mathrm{C}$, the transmitted E-Beam excited the plasma successfully.

The $50 \mathrm{~nm}$ lines and spaces resist pattern was fabricated on the chemically amplificated negative resist, SAL-601 ER-7 from Shipley Far East Ltd. with using the E-Beam patterning system JBX$6000 \mathrm{SG}(\mathrm{JEOL} \mathrm{Co}$.) where the resist thickness was decreased to $55 \mathrm{~nm}$ by optimizing baking and curing conditions.
The plasma etching through the resist pattern was performed under a negative bias voltage of $191 \mathrm{~V}$ in the E-Beam excited plasma of $\mathrm{CF}_{4}$ at a pressure of $20 \mathrm{mTorr}$, an transmitted E-Beam acceleration voltage of $6 \mathrm{kV}$, a transmitted E-Beam current of $1 \mathrm{~mA}$. Through $50 \mathrm{~nm}$ resist pattern, $\mathrm{Si}$ wafer etching were successfully performed as shown in Fig. 2, where the resist is still remained on the Si wafer after the resist stripping, but it was confirmed that the resist pattern was transferred to Si wafer.

The experimental results that the resist with a thickness of $55 \mathrm{~nm}$ sustained the pattern structure during the plasma etching is important. This fact means that the plasma was maintained at the lower level to prevent the damage of the resist. It is expected that the plasma will be utilized in a future for a nanometer pattern fabrication.

\section{Conclusion}

In the experiments, a new resist of pulsed plasma graft-polymerized styrene showed an improved resist sensitivity of $50 \mu \mathrm{C}$ and $200 \mathrm{~nm}$ pattern structure and a new plasma etching method realized a $50 \mathrm{~nm}$ pattern etching on silicon wafer with using $55 \mathrm{~nm}$ thickness of the resist of SAL601 ER-7. However the plasma polymerized resist was not evaluated for the new etching reactor in this study. However the possibility of use was confirmed by the experiments.

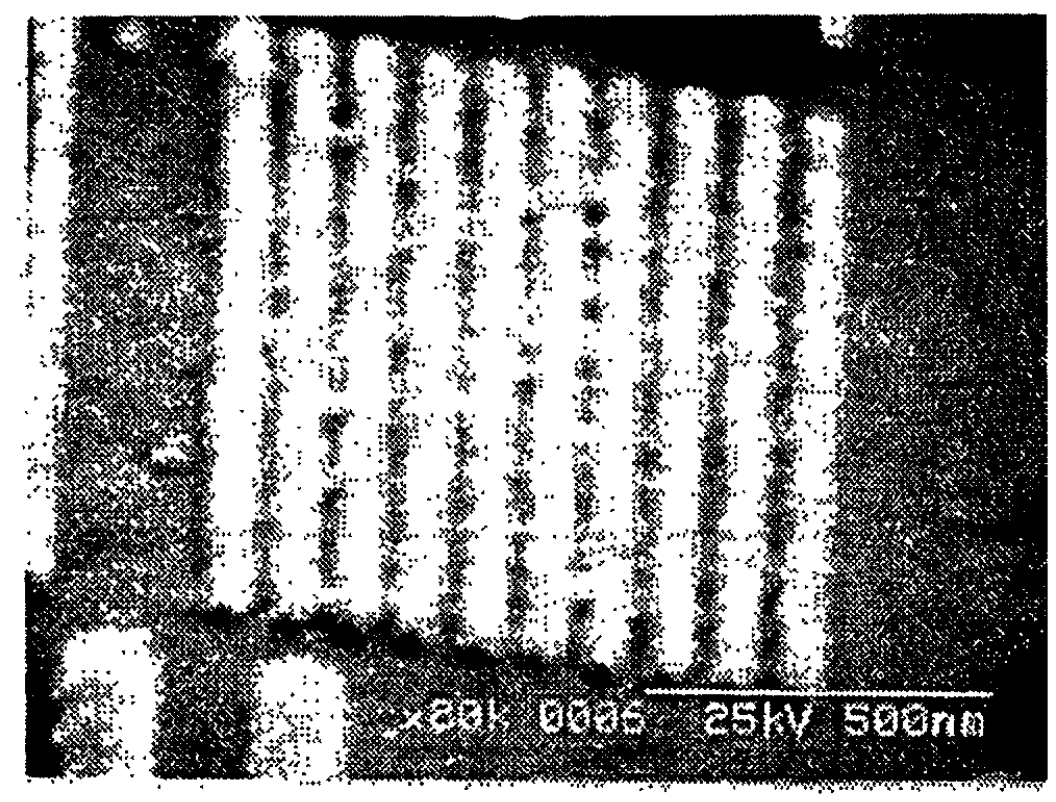

Fig. 2. $50 \mathrm{~nm}$ Pattern after EBEP Etching 


\section{Acknowledgement}

All of the experiments reported here were performed at the Center for Co-operative Research in Advanced Science and Technology( Prof. N. Hayakawa, Director). Polyimide SP-811 was provided from Toray Co. Inc.. We express great thanks to all of people concerned.

\section{References}

1. K. Yano, T. Ishii, T. Hashimoto, T. Kobayashi, F. Murai and K. Seki; IEEE Trans. Electron. Devices, 41(9)pp. 1628-1638(1994).

2. A. Ohata, H. Niiyama, T. Shibata, K. Nakajima and A. Toriumi; Jpn. J. Appl. Phys., 34, pp. 4485-4487(1995).

3. K. Matsumoto; Physica B 227, pp. 9294(1996).

4. Y. Takahashi, S. Horiguchi, A. Fujiwara and K.
Murase; Physica B 227, pp. 105-108(1996).

5. H. Takenouchi, T. Uchida and S. Morita; J. Photopolymer Sci. and Tech., 9(4)pp.659662(1996).

6. S. Morita, T. Naganawa, J. Kim, D. Lee and G. Vinogradov; Proc. of 3rd Int. Conf. on Prop. and Appl. of Dielectric Materials, July 8-12, Tokyo, pp. 635-638(1991).

7. G. Vinogradov, G. Yusa, T. Uchida and S. Morita; 14th Conf. on Photopolymer Sci. and Tech., June 24-27, Chiba, (1997).

8. R. Inanami, T. Naganawa, C. Shao and $S$. Morita; J. IEE Japan(in Japanese), C 113(9)pp. 669-677(1993).

9. R. Inanami, C. Shao and S. Morita; J. Electrochem. Soc., 141(9), pp. 2541-2544(1994).

10. R. Inanami S. Morita; J. Electrochem. Soc., 143(11), pp. 3752-3754(1996). 